\title{
Corrigendum to "A Preliminary Investigation of User Perception and Behavioral Intention for Different Review Types: Customers and Designers Perspective"
}

\author{
Atika Qazi, ${ }^{1}$ Ram Gopal Raj, ${ }^{1}$ Muhammad Tahir, ${ }^{2,3}$ Mehwish Waheed, ${ }^{1}$ \\ Saif Ur Rehman Khan, ${ }^{1}$ and Ajith Abraham ${ }^{4}$ \\ ${ }^{1}$ Faculty of Computer Science and Information Technology, University of Malaya, 50603 Kuala Lumpur, Malaysia \\ ${ }^{2}$ Faculty of Information Science and Technology, COMSATS Institute of Information Technology (CIIT), Park Road, \\ Islamabad 44000, Pakistan \\ ${ }^{3}$ Faculty of Computing and Information Technology, King Abdulaziz University, North Jeddah Branch, Jeddah 21589, Saudi Arabia \\ ${ }^{4}$ Machine Intelligence Research Labs, Scientific Network for Innovation and Research Excellence, Auburn, WA 98071, USA \\ Correspondence should be addressed to Atika Qazi; atika@siswa.um.edu.my \\ Received 26 March 2015; Accepted 1 April 2015 \\ Copyright (C) 2015 Atika Qazi et al. This is an open access article distributed under the Creative Commons Attribution License, \\ which permits unrestricted use, distribution, and reproduction in any medium, provided the original work is properly cited.
}

The author name Mahwish Waheed should be replaced with Mehwish Waheed.

In the body of the paper,

$$
\begin{aligned}
& \text { (from } \beta=.50, P=.000 \text {, to } \beta=.3, P=.000 \text { ) should } \\
& \text { be replaced with the following values (from } \beta=.75 \text {, } \\
& P=.000 \text { to } \beta=.41, P=.001 \text { ); } \\
& \text { (from } \beta=.25, P=.0 \text {, to } \beta=.13 \text {, n.s.) should } \\
& \text { be replaced with the following values (from } \beta=.19 \text {, } \\
& P=.05 \text { to } \beta=.06, \text { n.s.); } \\
& \text { (from } \beta=.60, P=.000 \text {, to } \beta=.26, P=.000 \text { ) should } \\
& \text { be replaced with the following values (from } \beta=.24 \text {, } \\
& P=.011 \text { to } \beta=.57, P=000 \text { ); } \\
& \text { (from } \beta=.20, P=.04 \text {, to } \beta=.001 \text {, n.s.) should } \\
& \text { be replaced with the following values (from } \beta=.70 \text {, } \\
& P=.000 \text { to } \beta=.001 \text {, n.s.). }
\end{aligned}
$$

Figure 1 is corrected as follows. 


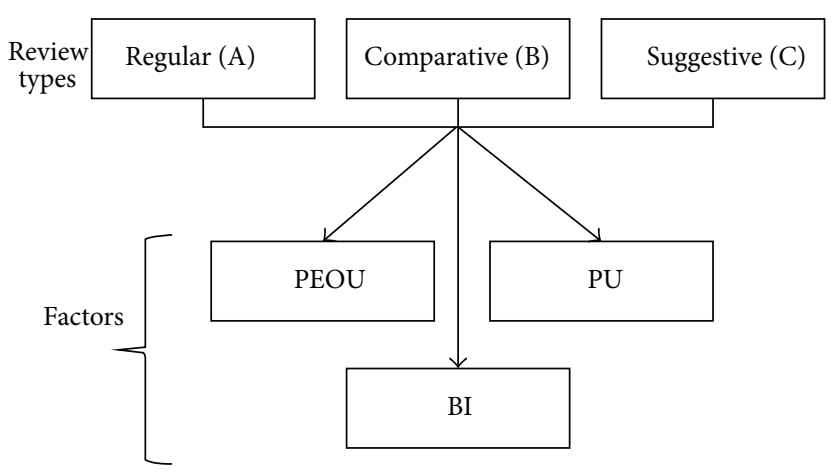

FIgURE 1: The proposed model. 

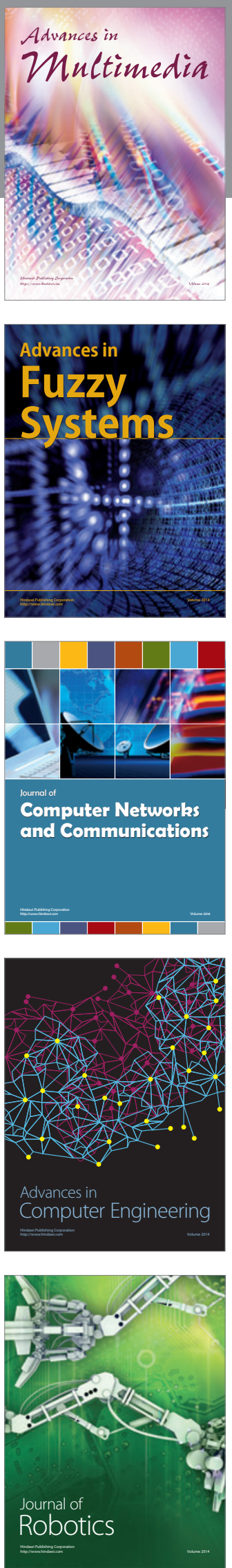

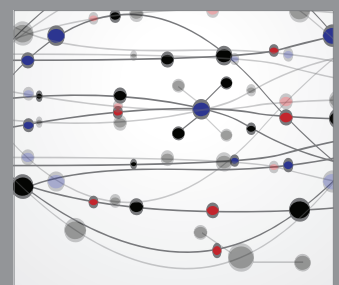

The Scientific World Journal
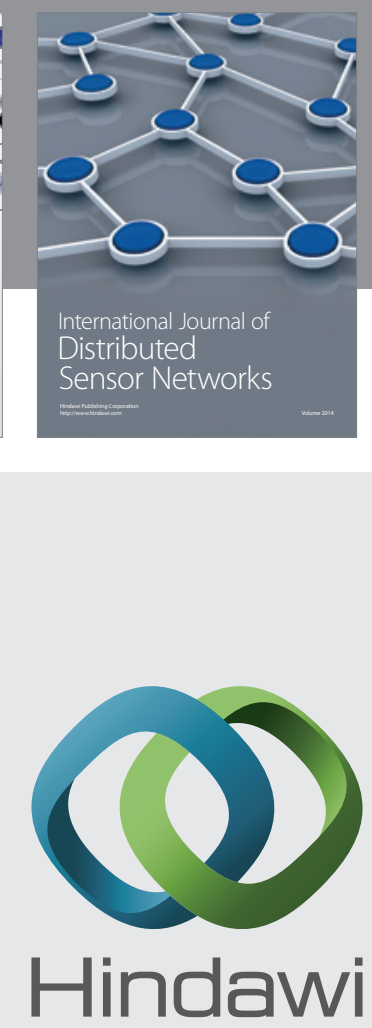

Submit your manuscripts at

http://www.hindawi.com
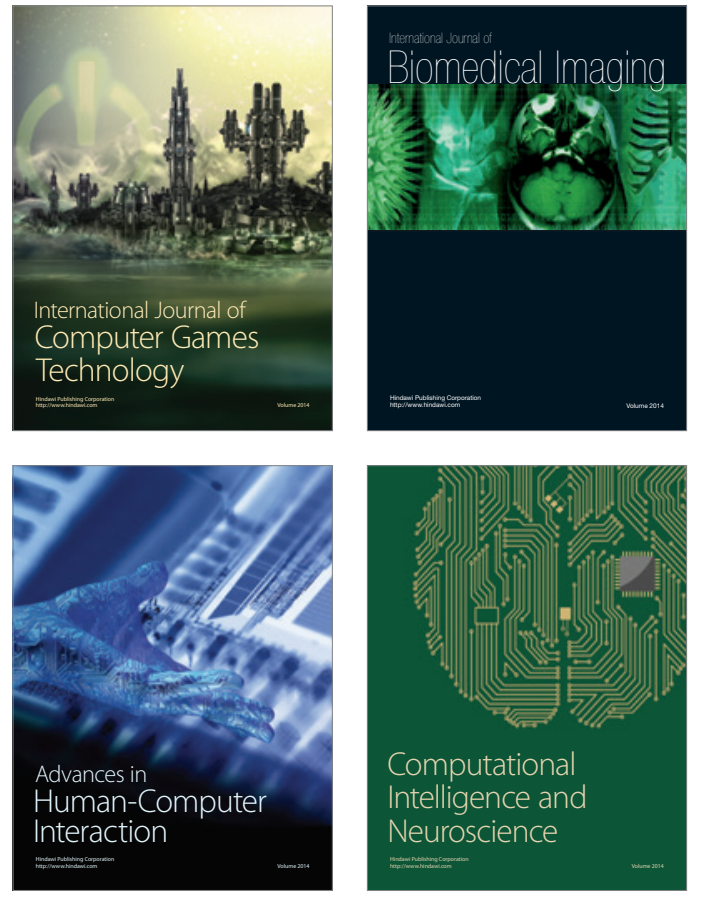
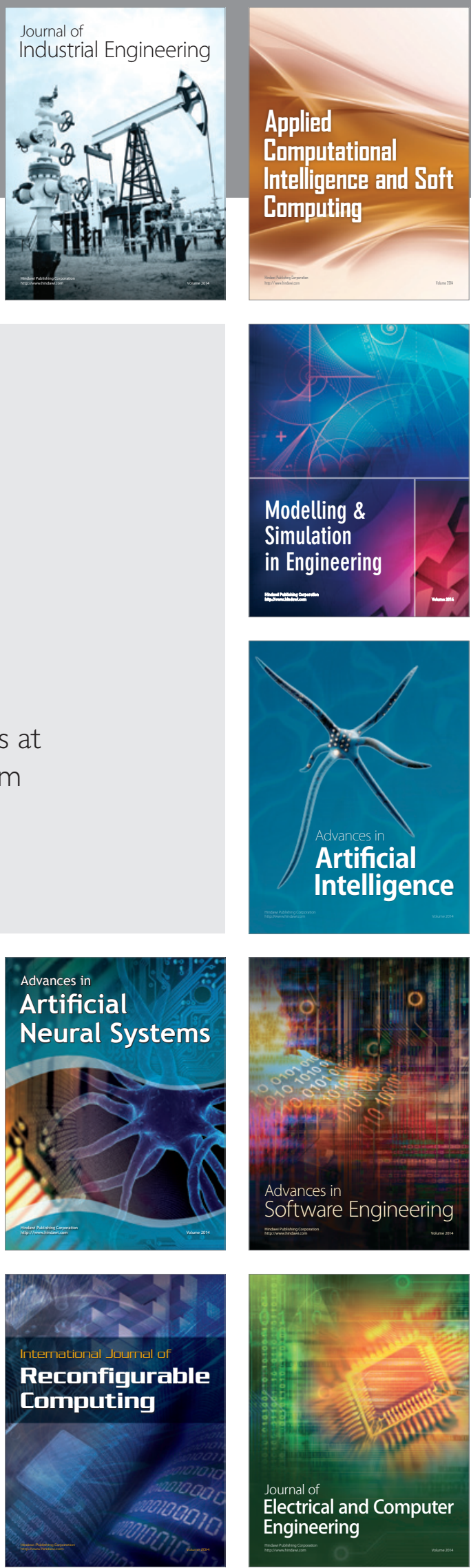